\title{
Overview of Carbon Dioxide Control Issues During International Space Station/Space Shuttle Joint Docked Operations
}

\author{
Christopher M Matty ${ }^{1}$ \\ NASA Lyndon B. Johnson Space Center, Houston, Texas, 77058
}

\begin{abstract}
Crewed space vehicles have a common requirement to remove the carbon dioxide $\left(\mathrm{CO}_{2}\right)$ created by the metabolic processes of the crew. The space shuttle [Space Transportation System (STS)] and International Space Station (ISS) each have systems in place that allow control and removal of $\mathrm{CO}_{2}$ from the habitable cabin environment. During periods in which the space shuttle is docked to the ISS, known as "joint docked operations," the space shuttle and ISS share a common atmosphere environment. During this period, an elevated amount of $\mathrm{CO}_{2}$ is produced through the combined metabolic activity of the STS and ISS crews. This elevated $\mathrm{CO}_{2}$ production, together with the large effective atmosphere created by collective volumes of the docked vehicles, creates a unique set of requirements for $\mathrm{CO}_{2}$ removal. This paper will describe individual $\mathrm{CO}_{2}$ control plans implemented by STS and ISS engineering teams, as well as the integrated plans used when both vehicles are docked. The paper will also discuss some of the issues and anomalies experienced by both engineering teams.
\end{abstract}

\section{Carbon Dioxide Removal System Overview}

$\mathrm{T}$ his paper will focus on the joint docked operations period during which the space shuttle and International Space Station (ISS) are docked together. All discussion will be assumed to relate to the two-vehicle system of ISS and the Space Transportation System (STS; synonymous with the space shuttle) with the hatch at the docked interface open and cabin atmosphere shared between the two vehicles.

On the habitable section of ISS, carbon dioxide $\left(\mathrm{CO}_{2}\right)$ is scrubbed by the carbon dioxide removal assembly (CDRA) on the United States On-orbit Segment (USOS) and the Vozdukh system in the Russian segment.

On the habitable section of the space shuttle, lithium hydroxide $(\mathrm{LiOH})$ canisters serve as the primary means of scrubbing $\mathrm{CO}_{2}$ from the cabin environment. When the space shuttle is docked to the ISS, the two vehicles share both a common habitable environment and a common atmosphere. The habitable volume of the STS vehicle is comparatively small in relation to the ISS, so the shared environment allows the CDRA on the USOS to share in much of the STS crew members' metabolic $\mathrm{CO}_{2}$ load, reducing required $\mathrm{LiOH}$ canister use.

When crew members are participating in an extravehicular activity (EVA), they commonly use metal oxide (Metox) cartridges to scrub $\mathrm{CO}_{2}$ from the spacesuit as well as in the airlock environment. While the crew members are participating in the EVA, metabolic $\mathrm{CO}_{2}$ is cycled through a Metox canister contained within their suits. After the EVA has been completed, the Metox canisters are heated and regenerated, at which point the collected $\mathrm{CO}_{2}$ is released to the ISS cabin atmosphere. This released $\mathrm{CO}_{2}$ is then scrubbed from the ISS atmosphere by the CDRA.

\section{A. Carbon Dioxide Removal Assembly}

The CDRA is the primary $\mathrm{CO}_{2}$ removal system for the ISS USOS. It operates as a dual-bed, zeolite-based $\mathrm{CO}_{2}$ removal system that uses an alternating cycle. The two beds, in this case known as desiccant-adsorbent beds, operate on a cycle with one adsorbing $\mathrm{CO}_{2}$ from the cabin air while the other desorbs previously accumulated $\mathrm{CO}_{2}$ to space vacuum, which will be described as follows. For the sake of this description, the desorbing bed will be referred to as Bed 1 while the adsorbing bed is referred to as Bed 2 (see Fig. 1).

\footnotetext{
${ }^{1}$ Atmosphere Revitalization Subsystem Manager, EC6 ISS ECLSS, NASA Lyndon B. Johnson Space Center, Houston, Texas 77058 .
} 


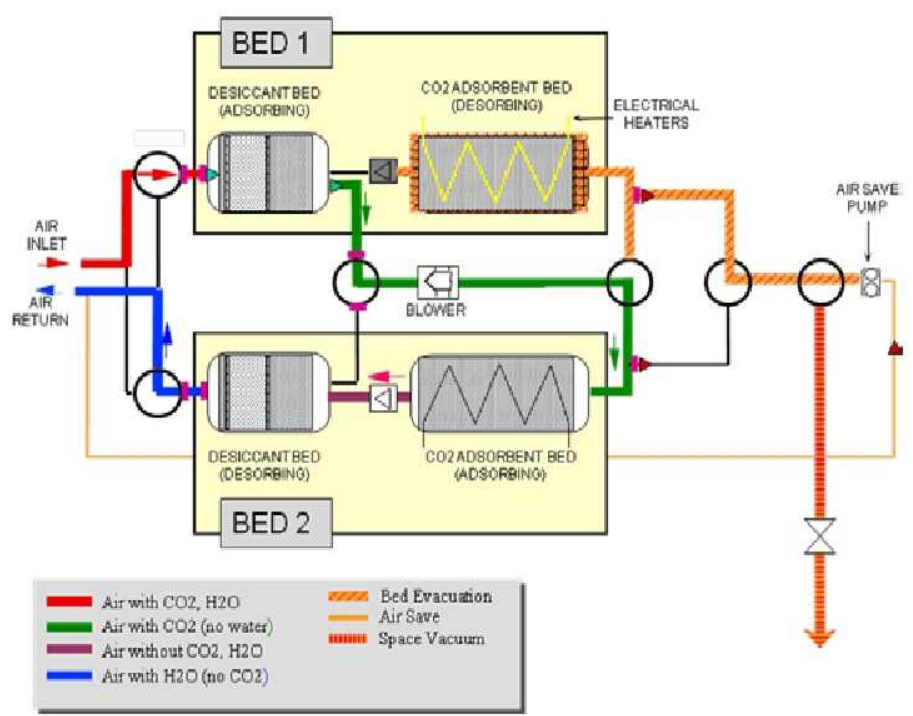

Figure 1. CDRA schematic. Architecture of the CDRA, showing desiccant-adsorbent $\mathrm{Bed} 2$ adsorbing $\mathrm{CO}_{2}$ from the cabin and desiccant-adsorbent Bed 1 desorbing to the space vacuum. ${ }^{2}$ desorbs to space. When the valves close, the bed that is transitioning from adsorbing to desorbing will be full of air at ambient pressure. If this air is immediately exposed to space vaccum, it will be lost overboard. To prevent loss of air inside the bed, the air save pump brings the bed to initial vaccum and returns the removed air to the cabin. Thus, CDRA effectively pumps $\mathrm{CO}_{2}$ overboard without losing significant amounts of cabin air.

\section{B. Vozdukh}

Vozdukh is the primary $\mathrm{CO}_{2}$ removal system for the Russian segment of ISS. It operates on a similar principal to CDRA, with the exception that it has three beds and uses an amine-based adsorbent rather than a zeolite. This paper is written from the standpoint of USOS operations; therefore because Vozdukh is a Russian system, it will not be discussed in technical detail in this paper.

\section{Lithium Hydroxide}

These cylindrical metal canisters are filled with $\mathrm{LiOH}$, with a central annulus to allow airflow. They are installed in a blower system that provides motive airflow through both the can and the LiOH contained within. The exterior and interior circumferential surfaces of the cylinder are perforated, and airflow moves from the inner annulus into the $\mathrm{LiOH}$ material before it exhausts through the outer perimeter of the canister. $\mathrm{LiOH}$ reacts with ambient humidity and $\mathrm{CO}_{2}$ to create lithium carbonate $\left(\mathrm{Li}_{2} \mathrm{CO}_{3}\right)$. Unlike the zeolite and amine materials used in the CDRA and Vozdukh respectively, the conversion of $\mathrm{LiOH}$ to $\mathrm{Li}_{2} \mathrm{CO}_{3}$ is permanent; i.e., the $\mathrm{LiOH}$ canisters have a limited consumable life. The $\mathrm{LiOH}$ canisters on board the space shuttle are changed at regular intervals to provide fresh $\mathrm{LiOH}$ for reaction. The consumable nature of $\mathrm{LiOH}$ canisters means that a stock of canisters must be loaded aboard the vehicle prior to a mission according to planned $\mathrm{CO}_{2}$ scrubbing requirements, and $\mathrm{LiOH}$ canister use must be closely rationed during flight.
Inlet air from the cabin flows into CDRA Bed 1. Because the zeolite material will react preferentially with ambient moisture over atmospheric $\mathrm{CO}_{2}$, the incoming $\mathrm{CO}_{2}$-laden air must be desiccated prior to zeolite exposure. Incoming air is first flowed through the desiccant portion of Bed 1 before it is routed through the motive blower and into the zeolite portion of Bed 2 for $\mathrm{CO}_{2}$ removal. Scrubbed air is then flowed outward over the previously saturated desiccant portion of Bed 2, absorbing previously removed moisture and returning it to the cabin environment as the scrubbed air leaves the CDRA. Meanwhile, the adsorbent portion of Bed 1 is isolated from both the desiccant portion of Bed 1 and the cabin environment. The isolated adsorbent portion of Bed 1 is exposed to space vacuum and heated, causing the adsorbed $\mathrm{CO}_{2}$ to be released and vented to space. When the adsorbent portion of Bed 2 becomes saturated, the valves are reconfigured and the two beds switch roles; i.e., Bed 1 adsorbs and Bed 2

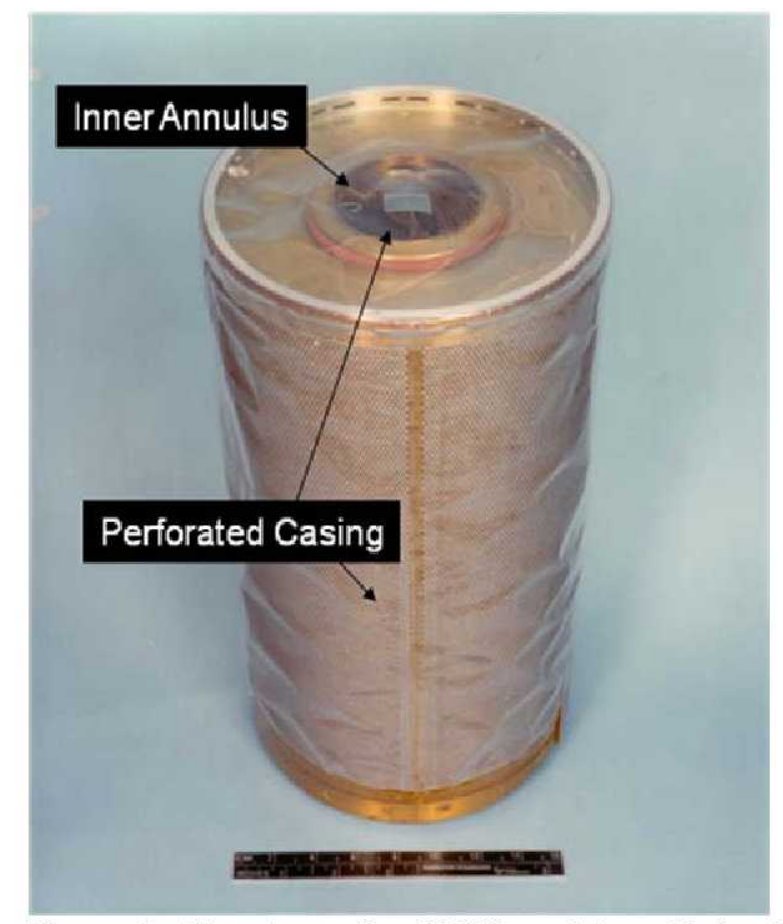

Figure 2. Structure of a $\mathrm{LiOH}$ canister. Ruler is $16 \mathrm{~cm}$ for scale. ${ }^{l}$ 


\section{Booster Fan}

There is a dedicated duct system, known as the "booster fan", which pulls high- $\mathrm{CO}_{2}$ air out of the space shuttle vehicle into the ISS. The booster fan is located in the tunnel between the shuttle middeck and the shuttle airlock, which leads to the orbiter docking system (ODS) hatch, which interfaces with the ISS. The booster fan duct pulls air out of the space shuttle middeck through the ODS hatch and into the ISS, where it can be scrubbed by the CDRA; this displacement also helps to draw "clean" low- $\mathrm{CO}_{2}$ air back into the space shuttle habitable volume. The booster fan is intended to reduce STS dependence on $\mathrm{LiOH}$ and thus reduce the amount of $\mathrm{LiOH}$ used during docked operations by distributing the load of the STS crew across the ISS CDRA and Vozdukh scrubbing systems. ${ }^{2}$

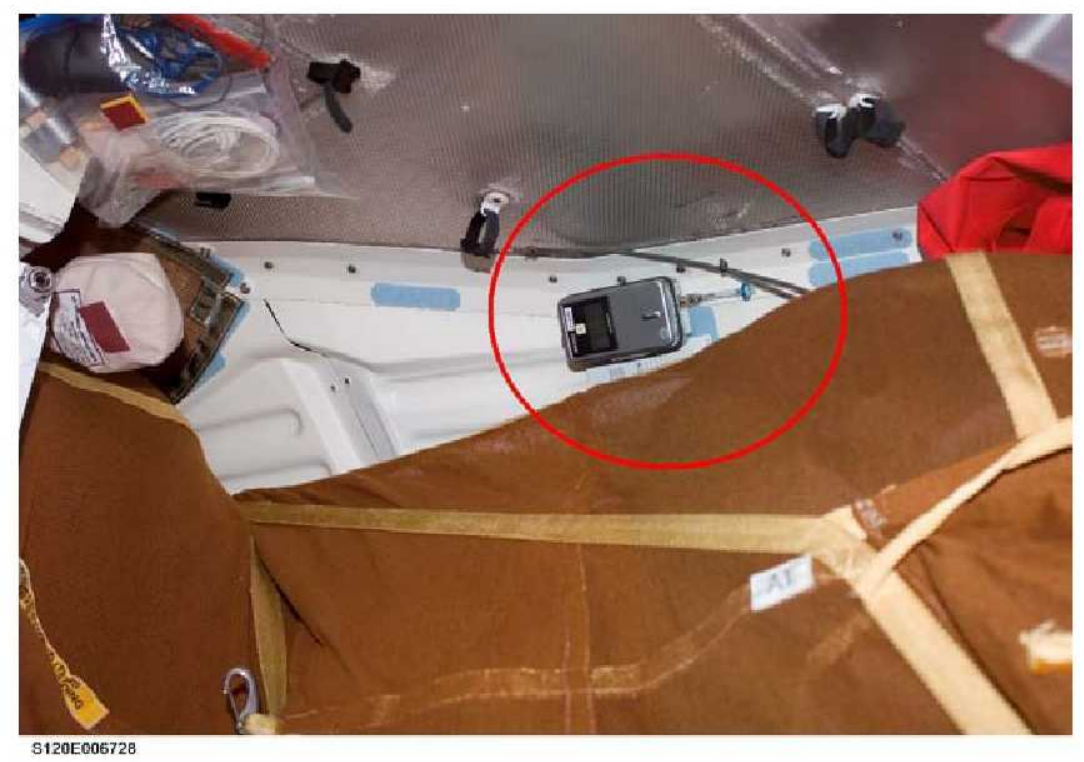

Figure 3. A CDMK probe (circled in red) placed in a confined area to record $\mathrm{CO}_{2}$. Image Credit: $\mathrm{NASA}$

\section{E. Major Constituent Analyzer}

Atmospheric $\mathrm{CO}_{2}$ levels on the USOS are primarily measured by the Major Constituent Analyzer (MCA). The MCA is a mass spectrometer which uses a plumbing system integrated into the ISS to sample multiple locations in the ISS habitable cabin environment. MCA allows real-time $\mathrm{CO}_{2}$ measurement at multiple fixed points in the habitable cabin volume. MCA data is telemetered to the Mission Control Center (MCC) to allow ground controllers to continuously monitor the ISS cabin environment in real time and also to record and track $\mathrm{CO}_{2}$ constituency data in the long-term. MCA has a high level of accuracy, but can only measure gas constituency at fixed points which are plumbed for sample taking.

\section{F. Carbon Dioxide Monitoring Kit}

The Carbon Dioxide Monitoring Kit (CDMK) is an auxiliary monitoring system consisting of a portable probe which interfaces with a laptop. The $\mathrm{CDMK}$ uses infrared sensing to measure $\mathrm{CO}_{2}$, and can be moved by the crew to any location in the cabin environment. (see Fig. 3). CDMK probes can be deployed by the crew as a stationary probe, which provides a profile of $\mathrm{CO}_{2}$ levels in this particular location. The probe can also be worn by a crew member as he or she carries out daily mission activities, in order to provide a profile of the various $\mathrm{CO} 2$ levels experienced by that crew member. The CDMK measures at 5 minute intervals, and must be activated and placed by the crew as part of a directed activity, after which $\mathrm{CO}_{2}$ measurements are recorded manually by the crew and communicated vocally to the ground controllers, or manually downloaded to a laptop and the data file transmitted to the ground. The CDMK is useful for providing general measurements of $\mathrm{CO}_{2}$ levels at a specified location, allowing direct measurements of trouble spots where high $\mathrm{CO}_{2}$ concentrations are suspected. However, CDMK use is only viable in very specific cases because of the large amount of crew time required to deploy and collect probes and then process the resultant data, and the relatively small amount of data collected. Additionally the CDMK records measurements with much larger time spacing than the MCA, so overall data resolution is much lower.

\section{Operational Issues and Considerations}

As discussed previously, three major $\mathrm{CO}_{2}$ scrubbing systems are to be considered in the jointly docked ISS/STS vehicle system. These systems are CDRA and Vozdukh on the ISS and LiOH on the space shuttle. When the two vehicles are docked, typically 10 to 13 crew members are on board, with six to seven crew members being on the STS and three to six on the ISS. These crew members are free to move between the docked vehicles as required for 
mission operations. The habitable volume of the ISS is approximately $790 \mathrm{~m}^{3}$, and the habitable volume of the space shuttle is approximately 70 $\mathrm{m}^{3}$, so the total habitable volume of the docked vehicles can be considered at $860 \mathrm{~m}^{3}$.

\section{A. Inter-module considerations}

The ISS atmosphere environment is mixed and cycled via a system of air handlers known as the intermodule ventilation (IMV) system. Because of the zero-g environment in Earth orbit, gases do not flow and settle due to density differences as they do in a typical one-g Earth environment. IMV provides a primary motive force for atmospheric gases in the habitable cabin environment, allowing $\mathrm{CO}_{2}$ laden air to reach the intake points of

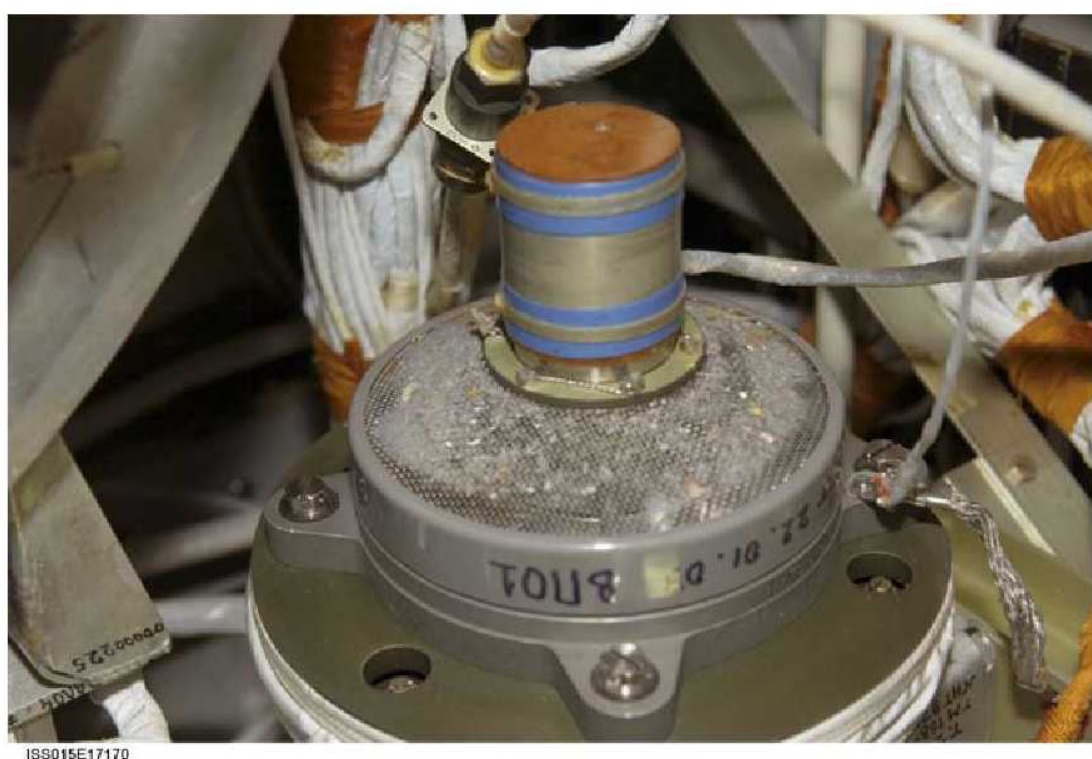

Figure 4. Russian BחO fan in Service Module exhibiting dust and debris accumulation Image Credit: NASA scrubbing systems, and allowing the freshly scrubbed exhaust air to be distributed throughout the cabin. IMV hardware frequently collects dust and debris from the cabin environment, which occludes airways and leads to reduced flow. (see Fig. 4) The crew is occasionally directed to inspect IMV hardware for excessive and clean IMV hardware when dust accumulation is found. Significant improvements in cabin ventillation are typically noted when IMV hardware has been cleaned

Due to the nature of mission operations, many crew activities require that more than one crew member be in a given location, thereby creating inconsistencies in the local atmospheric density of metabolic $\mathrm{CO}_{2}$. These localized $\mathrm{CO}_{2}$ density variations will ideally be mixed and normalized by the IMV system. However, several occurrences of $\mathrm{CO}_{2}$ "pockets" have been identified as localized areas of high-concentration $\mathrm{CO}_{2}$. These pockets have been especially problematic in the STS habitable volume, likely as a result of the small volume and concentrated crew loading. The six to seven STS crew members may spend a disproportionate amount of time in the smaller STS volume compared to the three to six ISS crew members in their significantly larger station volume. Airflow issues are also complicated by the fact that the space shuttle serves as a supply/return vehicle for the ISS and thus often experiences a large amount of airflow obstruction in the form of stowed hardware and cargo. The multiple possible configurations of crew members, hardware, and cargo mean that all possible configurations cannot be accurately modeled; leaving much potential for localized flow stagnations that may collect $\mathrm{CO}_{2}$.

Stowage is another major consideration in cabin airflow. Stowed hardware is a necessity in all space vehicles, but is an especially critical consideration as the ISS grows and becomes more active as a scientific labaoratory and functional outpost. Stowage on board the ISS and space shuttle are tracked and carefully controlled, but the sheer amount of hardware and relatively small avaialble cabin volume makes this a difficult proposition. This is particularly difficult during joint docked operations, as the space shuttle delivers large amount of new hardware to ISS, and equally large quantities of hardware are transferred back to the space shuttle vehicle to be returned to earth. The back and forth transfer of hardware means that items which would otherwise be trucked away are gathered together in the open cabin environment, providing occlusion to good airflow. (see Fig. 5) This random arrangement of large cargo items is impossible to accurately model, and yet leaves infinite possibilites for localized stagnations and potential high $\mathrm{CO}_{2}$. pockets.

\section{B. Sleep Scenarios}

As stated previously, IMV provides the primary motive force for mixing and distributing air through the habitable vehicle volume. A crew member also naturally disturbs the atmosphere as he/she moves about, helping to mix the ambient gasses. Activity and movement further naturally cause crew members to relocate to new areas, encountering fresh atmosphere and leaving exhaled metabolic $\mathrm{CO}_{2}$ behind. 
When a crew member is sleeping, he/she is immobile for an extended period of time. Again, gases do not settle due to density differences in a zero-g environment. Dense $\mathrm{CO}_{2}$ does not settle downward as it would in a one-g environment so, without motive ventilation, a stationary crew member will tend to create a localized pocket of exhaled $\mathrm{CO}_{2}$ around his/her face and head. Crew members may deploy personal fans to blow across their faces as a matter of personal preference, which helps to mitigate this effect.

The ISS crew typically sleeps on board station, while the STS crew sleeps on board shuttle. The six to seven STS crew members sleeping in the space shuttle create a high- $\mathrm{CO}_{2}$ load in the relatively small 70 $\mathrm{m}^{3}$ habitable volume. The

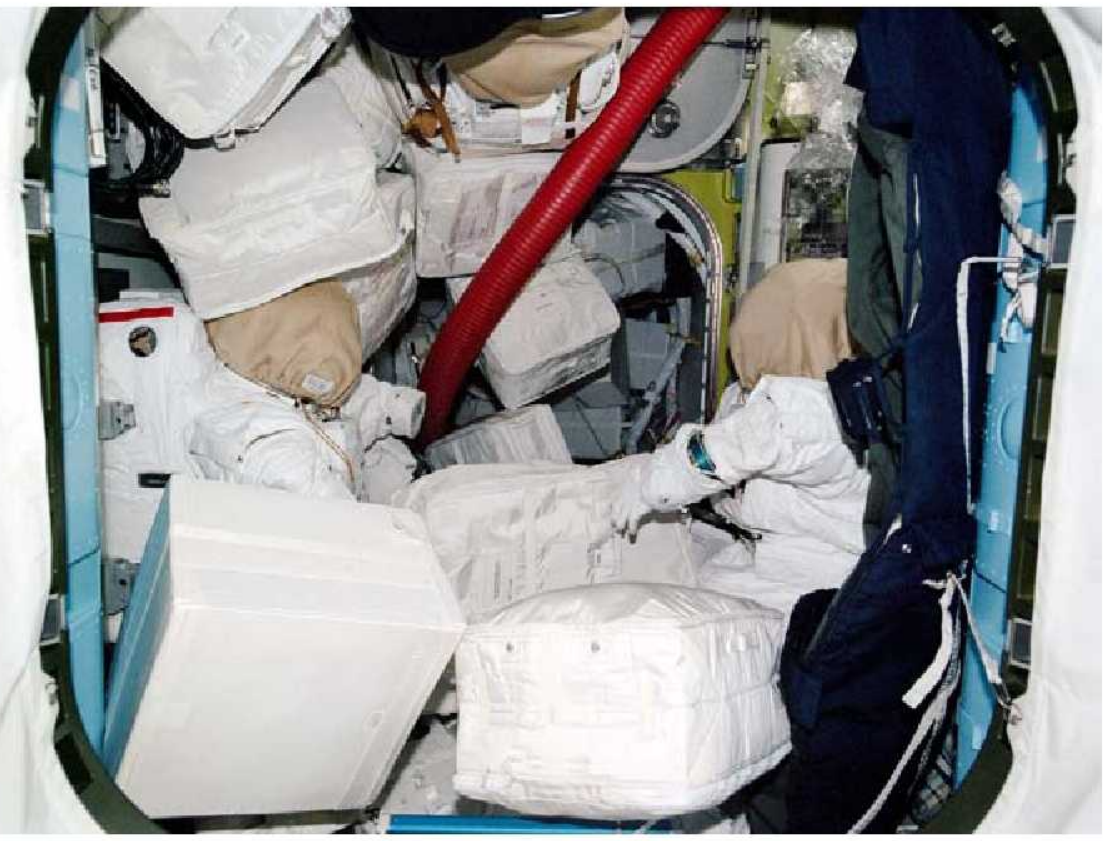

Figure 5. Interior of the Node1 module during the UF-1 docked mission, exhibiting crowded stowage detrimental to cabin airflow. Image Credit: NASA

CDRA has enough $\mathrm{CO}_{2}$ removal capacity to accommodate most of the $\mathrm{CO}_{2}$ exhaled by the sleeping STS crew, but the significant physical distance between the CDRA in the ISS USOS and the STS volume means that providing necessary ventilation can be problematic.

$\mathrm{LiOH}$ canisters are typically deployed on the space shuttle immediately before or immediately after the crew's sleep period to help lower the elevated local $\mathrm{CO}_{2}$ levels caused by crew sleep.

\section{Vozdukh Scenarios}

Vozdukh was initially the primary $\mathrm{CO}_{2}$ removal system for the ISS. As stated previously, Vozdukh has three adsorbent beds that contain an amine material used to scrub $\mathrm{CO}_{2}$. Early in the ISS's operational life, one of these beds failed, leaving Vozdukh operational on two beds. Due this two-bed operational state, Vozdukh is not operating at full potential. Vozdukh's capacity to scrub $\mathrm{CO}_{2}$ has diminished through the life of the ISS program, initially requiring a balance by the CDRA when the habitable atmosphere had a heavy crew load, and evolving into sharing much of the load with CDRA. As Vozdukh continued to degrade, CDRA has shouldered more and more of the $\mathrm{CO}_{2}$ load, to the point where CDRA functions as the primary system. Vozdukh is currently operating on two of its three beds in a severely degraded state, such that it only provides ancillary $\mathrm{CO}_{2}$ removal support to CDRA. There is a potential for the Vozdukh to be restored to full three-bed operation, which has been limited thus far by a lack of available spares and crew support. However, the option to repair Vozdukh will continue to be explored.

\section{Carbon Dioxide Removal Assembly Scenarios}

The CDRA has two desiccant-adsorbent beds that act in concert to provide $\mathrm{CO}_{2}$ scrubbing. CDRA function is fundamentally dependent on the ability to flow atmospheric gasses thorough these beds to allow $\mathrm{CO}_{2}$ scrubbing. As the zeolite and desiccant materials within the beds are in the form of loose pellets, however, a balance must be stuck to allow maximum possible airflow while still containing the adsorbent material within the bed. Early in the CDRA deployment, problems arose due to a lack of adsorbent containment. Loose zeolite material escaped from the beds, damaging and obstructing the valves within CDRA. This containment problem was addressed with a modified bed design.

CDRA has also experienced problems with zeolite occlusion within the beds, whereby zeolite dust works its way into orifices within the bed, eventually obstructing flow beyond functional levels. ${ }^{8}$ This problem has been attributed to both excessive zeolite dust creation within the bed, and to excessive mechanical obstruction leading to dust accumulation and eventual flow occlusion. ${ }^{8}$ Pressure across CDRA beds is carefully monitored to track the pressure rise over time, as flow obstruction is a gradual process. CDRA beds design has been revised to reduce zeolite dust 
accumulation, and a second redesign is currently under way to further mitigate zeolite obstruction, and to allow the crew to dismantle the CDRA bed on-orbit and clean any zeolite dust accumulation that may occur.

CDRA recently experienced a failure in one of the adsorbent bed heaters. CDRA internal temperature sensors indicated that the bed heaters were not being controlled to within their target range. The beds were also not turning off at the end of the half cycle, leading to increased power draw and elevated temperatures within the adsorbent bed. ${ }^{6}$ This problem was initially thought to be an issue within the electronic heater controller unit, but was eventually found to be a short between one of the laminated heater sheets and the external case of the CDRA bed. ${ }^{6}$ The short was made possible by a compromised section in the heater sheet lamination, although it is not known at this time what caused the compromised section. ${ }^{6}$ The crew was able to access the wiring for the CDRA bed heater and isolate the damaged heater sheet by cutting its power leads. The revised CDRA bed designs will account for this heater anomaly once root cause is further understood.

A single CDRA was flown as part of the US LAB module of ISS, in place in the atmosphere revitalization rack. A second CDRA was flown on the 17A shuttle mission, which will be installed in the ISS Node 3 module. Since there are now 2 CDRA units on board ISS, and because the CDRA beds are being updated, a process has begun of alternately removing beds from one CDRA and replacing them with an updated design, during which period the other CDRA acts as the prime unit. Eventually there is planned to be 2 fully operational CDRAs with final-level revised beds in both units.

Because Vozdukh continues to operate in a two-bed mode, it cannot carry the metabolic load of a full ISS and STS crew. Therefore when only one CDRA is operational, a CDRA failure cases during joint docked operations create a shortfall in the ISS's $\mathrm{CO}_{2}$ removal capacity - a shortfall that must be made up by $\mathrm{LiOH}$ canister deployment. Because $\mathrm{LiOH}$ canisters are a limited consumable resource, this is an unfavorable option; therefore, nominal CDRA function is given a high priority. Since a single CDRA can remove $\mathrm{CO}_{2}$ for all six ISS crew, the risk to ISS $\mathrm{CO}_{2}$ control from CDRA failure will be greatly reduced once both CDRAs are fully operational.

\section{E. Lithium Hydroxide Scenarios}

$\mathrm{LiOH}$ is a consumable resource; meaning there is a limited amount of $\mathrm{CO}_{2}$ removal possible for a given number of $\mathrm{LiOH}$ canisters. It also has a relatively high mass, with each canister weighing approximately $7 \mathrm{lbs}$. fresh and $9 \mathrm{lbs}$. after use ( $\mathrm{LiOH}$ absorbs ambient water during reaction with $\mathrm{CO}_{2}$, thus accounting for most of this weight gain). As $\mathrm{LiOH}$ canisters are heavy, they incur a significant launch and return cost for STS operations that could otherwise be used for cargo. For this reason, it is sometimes deemed necessary to reduce the number of $\mathrm{LiOH}$ canisters flown on an STS mission to accommodate other cargo. Conversely, room is available on a given STS mission, additional $\mathrm{LiOH}$ canisters may be flown. A "stockpile" of $\mathrm{LiOH}$ canisters is stowed on board ISS that allows a depot operation to balance these over/under-runs in $\mathrm{LiOH}$ canisters on STS flights. When a space shuttle flight has more $\mathrm{LiOH}$ canisters than are needed for the mission, the canisters are added to the stockpile quantity on ISS, and some of these canisters are used when an STS flight is unable to fly sufficient $\mathrm{LiOH}$ to cover mission requirements.

Again, because $\mathrm{LiOH}$ canisters are a valuable consumable resource, use is limited whenever possible during joint docked operations. When CDRA and Vozdukh are able to handle the combined ISS and $\mathrm{STS} \mathrm{CO}_{2}$ load, $\mathrm{LiOH}$ use is restricted to limited nominal use- usually for STS crew sleep scenarios, as discussed earlier, and for contingency scenarios in which the CDRA or Vozdukh is compromised.

\section{Crew Considerations}

The crews of the ISS and space shuttle are the primary generators of $\mathrm{CO}_{2}$ in the habitable cabin atmosphere. Additionally, the health, safety and comfort of the crew members is the primary requirement for $\mathrm{CO}_{2}$ control and removal. As the ISS program has progressed, numerous considerations have arisen regarding the crews' relationship with $\mathrm{CO}_{2}$ in the habitable cabin atmosphere.

\section{A. General rules and limits}

As a general rule, $\mathrm{CO}_{2}$ in the ISS habitable cabin atmosphere is kept below $7 \mathrm{mmHg}$ partial pressure (760 torr cabin pressure) for short term exposure, with a long-term limit of $5.3 \mathrm{mmHg}$ as a long-term average. As a relative metric, the United States National Institute for Occupational Safety and Health (NIOSH) specifies a short term exposure limit of $22.8 \mathrm{mmHg}$ partial pressure and and $3.8 \mathrm{mmHg}$ partial pressure as a long-term average exposure. ${ }^{4}$

NIOSH limits are not directly comparable to ISS values because the average health of astronauts and cosmonauts is different to that of an average industry worker, and operational considerations are not directly comparable. NIOSH long-term average exposure limits are based on a time-weighted average exposure over a standard 40 hour work week, while ISS and STS crew are required to work and live continuously in the habitable cabin environment, 
so $\mathrm{CO}_{2}$ levels contribute to a constantly running average exposure. For operational purposes, ISS average exposure is typically considered over the past 5-7 days of mission operations.

US astronauts are trained in $\mathrm{CO}_{2}$ exposure and taught to recognize symptoms of hypercapnia $\left(\mathrm{CO}_{2}\right.$ toxicity), which can vary from individual to individual. ${ }^{3}$ During $\mathrm{CO}_{2}$ exposure training, astronauts are exposed to elevated levels of $\mathrm{CO}_{2}$ and directed to note their own individual symptoms, as well as the symptoms of fellow trainees. Typical hypercapnia symptoms include hedaches, nausea, and shortness of breath. ${ }^{3} \mathrm{CO}_{2}$ exposure training allows astronauts onboard the ISS and space shuttle to identify and report $\mathrm{CO}_{2}$ symptoms in a controlled scenario on the ground, so that they may recognize when they experience similar symptoms during a mission. Individual $\mathrm{CO}_{2}$ exposure symptoms are also noted by the flight surgeons as part of a medical history, so that training results may be referenced in the event of hypercapnia reports during a mission. Incidence of hypercapnia is typically reported by the crew to a flight surgeon during a private medical conference, and the flight surgeon then relays the indicent to flight controllers so that any necessary modifications may be made to vehicle systems.

\section{B. Crew operational issues}

Crew reports of symptoms have occurred since the beginning of the ISS program. One of the first instances occurred during the 2A.1 mission, when a crew member reported feeling symptoms similar to those experienced in $\mathrm{CO}_{2}$ exposure training. ${ }^{5}$ Since this time, ISS crews and STS crews on docked missions to ISS have reported $\mathrm{CO}_{2}$ related symptoms regularly. Because symptoms are usually reported to flight surgeons during private medical conferences, they are received secondhand by the ground control engineers and systems engineers. These incidents have lead to increasingly conservative operational postures by the flight surgeon group, as well as increased concerns from potential and current crew members regarding the risk and general occurrence of $\mathrm{CO}_{2}$ symptoms. This issue is still ongoing, and ISS and STS crew members still regularly report $\mathrm{CO}_{2}$ related symptoms.

There is a level of subjectivity to crew reports of $\mathrm{CO}_{2}$ symptoms, as flight surgenons cannot directly examine crew members and must rely on verbal reports. There is a history of $\mathrm{CO}_{2}$ symptom reporting when MCA and CDMK data suggest no elevated $\mathrm{CO} 2$ levels in the cabin environment, which makes identifying and remedying problems difficult for engineering teams, who similarly cannot directly examine the cabin environment. Both the medical and engineering teams are hindered by the long-distance evaluation techniques necessitated by spaceflight.

\section{Booster Fan Bypass}

During the flight stand-down period following the Columbia accident, the booster fan bypass concept was brought forward as a way to improve overall ventilation between the ISS and space shuttle vehicles during docked operations. Because the booster fan is powered by the space shuttle vehicle, running the booster fan is an impact to the consumable cryogenic fuel cells on the shuttle. Since the ISS has a relatively more abundant supply of electric power, it was suggested that turning the booster fan off would allow the shuttle rely on the ISS IMV systems and save cryogenic fuel.

The shuttle booster fan resides in the tunnel between the shuttle middeck and the shuttle airlock. The booster fan bypass configuration consists of disconnecting the booster fan from the circuit, and running a jumper duct directly from the middeck to the airlock volume. Because the booster fan resides between the shuttle middeck and the shuttle airlock (which also leads to ODS when the shuttle is docked to ISS), the booster fan bypass was useful even when the shuttle was not docked to ISS, and the bypass had been tried on multiple STS missions where the shuttle did not

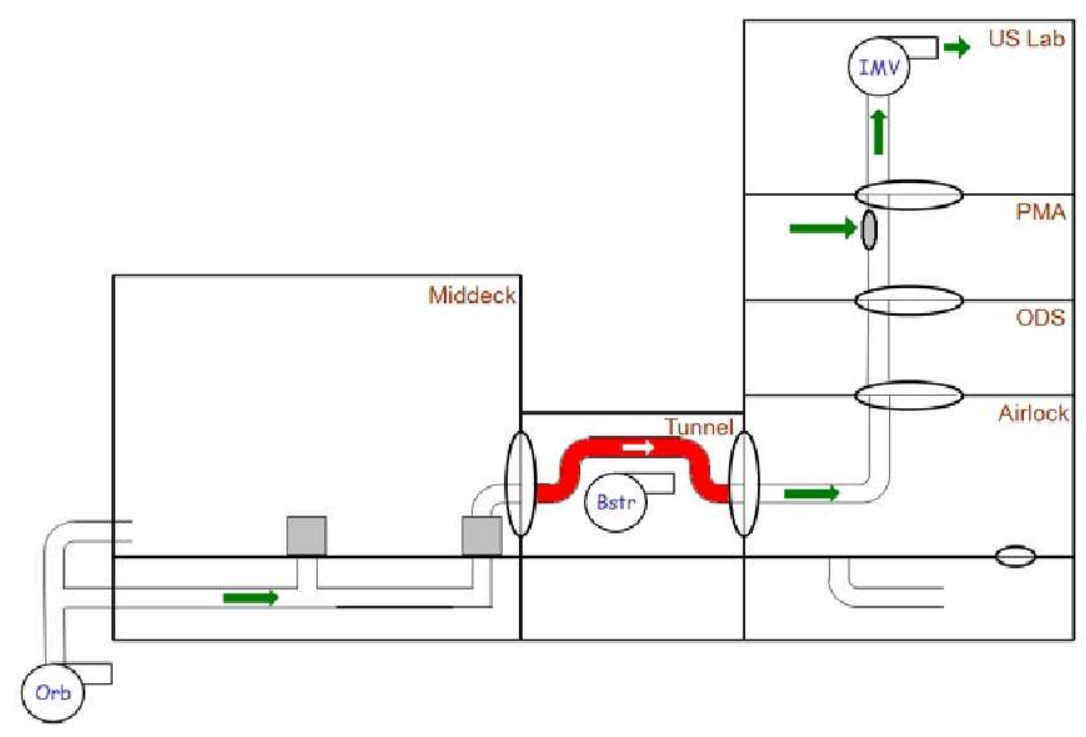

Figure 6. Diagram of Booster fan bypass configuration (bypass duct highlighted) ${ }^{7}$ 
dock to ISS. During these shuttle-only missions, there were no adverse $\mathrm{CO}_{2}$ effects reported by the crew, and significant savings were realized to available shuttle cryogenic fuels. ${ }^{7}$ Initial analysis suggested that the ISS IMV would be strong enough to sufficiently ventilate the shuttle middeck through the bypass duct.

The initial planned booster fan bypass operation would have the shuttle rely completely on ISS IMV, without using $\mathrm{LiOH}$ in the STS middeck to lower $\mathrm{CO}_{2}$ in the shuttle habitable volume. ${ }^{7}$ The booster fan bypass was initially tried on STS-114, which was the first "return to flight" mission after the Columbia accident.

The crew began to report adverse $\mathrm{CO}_{2}$ exposure symptoms almost immediately during the STS-114 docked mission. These symptoms were initially attributed to $\mathrm{CO}_{2}$ pockets caused by poor mixing due to the new ventilation configuration between the docked vehicles, but not to the booster fan bypass itself. Several different solutions were tried, including changing IMV vent configurations, altering the intake grill in the pressurized mating adapter (PMA2, see Fig. 6), and moving stowage on the both vehicles to alternate locations. The CDMK was deployed both in stationary configurations (see Fig 2.) and as a mobile unit worn by the astronauts, in order to measure $\mathrm{CO}_{2}$ levels experienced by the crew as they moved about the vehicle in their daily routine. Several problem areas were identified and systematically eliminated in this way, but the symptoms reported by the crew remained fairly constant over several concurrent missions. LiOH canister use on the STS middeck was re-instated after the initial booster fan bypass period, which alleviated some of the crew complaints but still left reports of symptoms. Eventually the booster fan bypass was abandoned, and booster fan operation was restored for the dual docked ops mission duration, combined with regularly scheduled $\mathrm{LiOH}$ canister use on the docked space shuttle.

\section{Conclusion}

Atmospheric $\mathrm{CO}_{2}$ control and removal will likely continue to be a major consideration for any crewed space flight mission, as well as many other applications in which humans are required to live and work in a closed environment. Crewed space vehicles present a unique opportunity to study the nature of metabolic processes, both through the constraints of a closed environment and through the new challenges presented by a physically isolated outpost in a space environment. The lessons learned from ISS provide unique insight into the evolution of $\mathrm{CO}_{2}$ management strategy. There is much variability introduced by the unknown parameters associated with prototype vehicles, combined with the subjective levels of $\mathrm{CO} 2$ "comfort" afforded by human crew members. While planning and modeling can be useful tools for predicting the cabin environment, there is no substitute for actual practice in the field. Even projects such as the booster fan bypass, which have been fielded successfully in one arena, can prove not to be viable in another apparently similar application. As human space exploration continues on longer and farther missions, all necessary life support equipment will have to develop to become more robust and more capable of sustaining long-term operation. As spaceflight vehicles proceed on longer missions, it is also likely that there will be significant decrease in the mass and power available to support $\mathrm{CO}_{2}$ removal systems. Thus any systems fielded on these vehicles will have a need to be thoroughly field-tested in prototype form before being sent on long-duration missions where replacement or large-scale overhaul will become unviable. Through the continuing work and study on the ISS and STS missions, $\mathrm{CO}_{2}$ control strategies will continue to be refined and tested.

\section{Acknowledgments}

Thank you to all the engineering, operational, scientific, and organizational teams that make the ISS and STS missions possible.

\section{References}

${ }^{1}$ Matty, C. M., Overview of Long-Term Lithium Hydroxide Storage aboard the International Space Station, ICES 2008-011969, NASA, 2008.

${ }^{2}$ Williams, D. E., Pate, L. R., Hoffman, C. The Lithium Hydroxide Management Plan for Removing Carbon Dioxide from the Space Shuttle while Docked to the International Space Station, ICES 2003-01-2491, NASA, 2003

${ }^{3}$ Medical Operations $\mathrm{CO}_{2}$ Exposure Training, $\mathrm{CO} 2$ 31074, NASA, 2005

${ }^{4}$ Chemical Sampling Information: Carbon Dioxide, http://www.osha.gov/dts/chemicalsampling/data/CH_225400.html, United States Department of Labor, National Institute for Safety and Occupational Health, 2010.

${ }^{5}$ James, J.T.. The Headache of Carbon Dioxide Exposures, ICES 2007-01-3218, NASA, 2007

8

American Institute of Aeronautics and Astronautics 
${ }^{6}$ Matty, C.M. CDRA Status for ULF3, presentation given to NASA ISS Vehicle Control Board, 2009

${ }^{7}$ Rogers, K. Booster Fan Bypass, presentation given to NASA STS-114 Flight Readiness Review, 2004

${ }^{8}$ Reysa, R.P., Lumpkin, J.P., El Sherif, D., Kay, R., Williams, D.E., International Space Station (ISS) Carbon Dioxide Removal Assembly (CDRA) Desiccant/Adsorbent Bed (DAB) Orbital Replacement Unit (ORU) Redesign., ICES 2007-01-3181, NASA, 2007

\section{Acronyms}

CDMK: $\quad$ Carbon dioxide monitoring kit

CDRA: carbon dioxide removal assembly

$\mathrm{CO}_{2}$ : carbon dioxide

EVA: extravehicular activity

IMV: $\quad$ inter-module ventilation

ISS: International Space Station

$\mathrm{Li}_{2} \mathrm{CO}_{3}$ : lithium carbonate

LiOH: lithium hydroxide

MCA: $\quad$ Major constituent analyzer

Metox: metal oxide

NIOSH: $\quad$ National Institute for Safety and Health

STS: $\quad$ Space Transportation System (Space Shuttle)

USOS: United States On-orbit Segment 